\title{
EFFICIENT VALIDATED METHOD OF HPLC TO DETERMINE ENALAPRIL IN COMBINATED DOSAGE FORM CONTAINING ENALAPRIL AND BISOPROLOL AND IN VITRO DISSOLUTION STUDIES
}

\author{
LILIYA LOGOYDA* \\ Department of Pharmaceutical Chemistry, I. Horbachevsky Ternopil State Medical University, Ukraine \\ Email: logojda@tdmu.edu.ua
}

Received: 16 Feb 2019, Revised and Accepted: 28 Mar 2019

ABSTRACT

Objective: A rapid and reproducible HPLC method has been developed for the determination of enalapril in experimental combined dosage forms containing bisoprolol and enalapril and for drug dissolution studies.

Methods: The separation was done using a column Hi Qsil $\mathrm{C}_{18}(4.6 \times 250 \mathrm{~mm}, 5 \mu \mathrm{m}$ particle size) and a mobile phase of methanol: phosphate buffer solution $(65: 35, \mathrm{v} / \mathrm{v})$, flow-rate of $1.0 \mathrm{ml} / \mathrm{min}$. The injection volume was $300 \mu \mathrm{L}$ and the ultraviolet detector was set at $225 \mathrm{~nm}$.

Results: The method was validated as per ICH guidelines. Under these conditions, enalapril was eluted at 5.33 min. Total run time was shorter than $6 \mathrm{~min}$. A linear relationship between the concentration and the area of chromatographic peaks of enalapril in the range of $1.250 \mathrm{mg} / \mathrm{ml}-10.000$ $\mathrm{mg} / \mathrm{ml}(7.500 \mathrm{mg} / \mathrm{ml}$ at $\mathrm{pH} 1.2)$ was established. Requirements for linear dependency parameters are performed in this case throughout the range of application of the technique. Linearity studies were conducted in a wide range of concentrations $(25-200 \%$ at $\mathrm{pH} 4.5$ and $6.8,25-150 \%$ at $\mathrm{pH} 1.2)$. In the medium with pH 1.2 release of enalapril from tablets in 5 min is $83.38 \%$, after 15 min- $94.11 \%$, after 30 min- $97.17 \%$; in medium with pH 4.5 the release of enalapril from tablets in 5 min makes $47.13 \%$, after 15 min-88.34\%, after 30 min-95.86 \%; in a medium with pH 6.8, the release of enalapril from tablets in $5 \mathrm{~min}$ is $71.04 \%$, and after $15 \mathrm{~min}-88.88 \%$, after $30 \mathrm{~min}-92.11 \%$.

Conclusion: A simple and sensitive HPLC method was developed for the estimation of enalapril in tablets containing enalapril and bisoprolol. The proposed method was applied successfully for quality control assay of enalapril in experimental tablets and in vitro dissolution studies.

Keywords: Enapalril, High-performance liquid chromatography, Dissolution study, Validation

(C) 2019 The Authors. Published by Innovare Academic Sciences Pvt Ltd. This is an open-access article under the CC BY license (http://creativecommons.org/licenses/by/4.0/) DOI: http://dx.doi.org/10.22159/ijap.2019v11i4.32584

\section{INTRODUCTION}

The dissolution test for solid dosage is one of the main pharmacotechnological tests used in the development, as well as during the life cycle of medicines. The main attention is paid to the study of the dissolution kinetics of the API, which is key in the selection and evaluation of the composition of the drug in the development process. The kinetics of dissolution or dissolution profiles is the dependence of the API concentration on the release time.

The study of dissolution profiles is also used to prove the in vitro equivalence of generic drugs (according to the bioweaver procedure), as well as the introduction of registration changes (introduction of an alternative substance or auxiliary substance manufacturer, changes in the technology and composition of the drug, introduction of new dosage, etc.) [1].

Enalapril is an angiotensin-converting enzyme (ACE) inhibitor widely used in the therapy of hypertension and heart failure. Enalapril is associated with a low rate of transient serum aminotransferase elevations and has been linked to rare instances of acute liver injury [2]. Chemical name of enapalril is (2S)-1-[(2S)-2[[(1S)-1-ethoxy-1-oxo-4-phenylbutan-2-yl]amino]propanoyl] pyrrolidine-2-carboxylic acid (fig. 1).

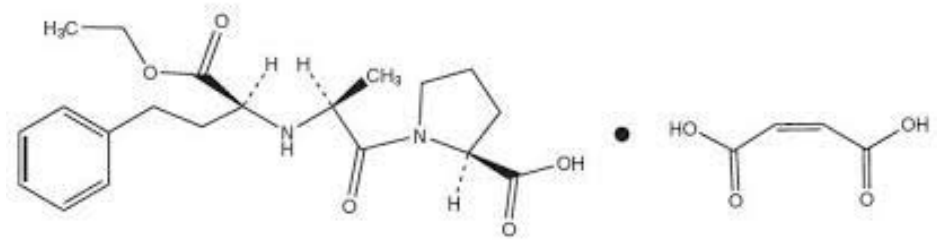

Fig. 1: The chemical structures of enalapril maleate

The State Pharmacopoeia of Ukraine (SPhU) has the monograph on the substance of enalapril maleate and on enalapril tablets. For identification of the substance of enalapril maleate, the SPhU offers the method of absorption spectrophotometry in the infrared region, quantitative determination-alkalimetry potentiometric titration. For identification of enalapril in tablets, the SPhU proposes TLC (mobile phase-a mixture of acetic acid of ice $P$, water $P$, butanol $P$ (15:25:60). For the quantitative determination of enalapril in tablets-HPLC/UV (mobile phase-a mixture of acetonitrile $\mathrm{P}$ and solvent (40:60), solvent-potassium dihydrogen phosphate solution $\mathrm{P}$, mobile phase rate- $1.0 \mathrm{ml} / \mathrm{min}$, detecting by the wavelength at $215 \mathrm{~nm}$ ).

There is an HPLC method described for the determination of enalapril in pharmaceutical preparations [2-5]. However, those methods are not developed for the determination of enalapril in dissolution studies while the dissolution profile of bisoprolol and another API from the combination drug product has not hitherto been reported in the literature [6-27]. In order to elucidate the 
dissolution profiles bisoprolol and enalapril, a validated HPLC method is required for determination of enalapril from tablets in dissolution matrix.

Therefore, the aim of this study was to develop and validate an efficient HPLC method for determination of enalapril and to introduce the dissolution profiles of tablets which contain bisoprolol and enalapril. Moreover, this new method could also be used for the routine analysis of enalapril in dosage forms, provided it is completely validated and rapid.

The method was validated according to guidelines and applied for the assay of enalapril from their combination tablet dosage form. Also, in vitro dissolution of enalapril containing tablets were performed to validate the suitability of the proposed method.

\section{MATERIALS AND METHODS}

\section{Instrumentation and chromatographic conditions}

The HPLC system consisted of Agilent 1260. A C18 column (Hi Qsil C18, $5 \mu \mathrm{m}, 4.6 \times 250 \mathrm{~mm}$ ) was used for separation and quantification. The mobile phase consisted of methanol: phosphate buffer solution $(65: 35, v / v)$ and was filtered through a $0.45 \mu \mathrm{m}$ filter and degassed before use. The injection volume was $300 \mu \mathrm{l}$ and the ultraviolet detector was set at $225 \mathrm{~nm}$. Analyses were run at a flow rate of 1.0 $\mathrm{ml} / \mathrm{min}$ at an ambient temperature $\left(25^{\circ} \mathrm{C}\right)$. The peak area was integrated automatically by using Empower ${ }^{\circledR}$ software. Under these conditions, enalapril was eluted at $5.33 \mathrm{~min}$. Total run time was shorter than $6 \mathrm{~min}$.

\section{Chemicals and reagents}

Standard enalapril was supplied by Refik Saydam National Public Health Agency. Methanol and phosphate buffer solution were of HPLC grade from Merck (Darmstadt, Germany) and all other reagents were analytical grade. Water obtained from the Milli-Q water system (Barnstead, USA) was used for the preparation of buffer and other aqueous solutions. Experimental tablets containing $5 \mathrm{mg}$ of enalapril and $2.5 \mathrm{mg}$ of bisoprolol were developed by Prof. Kachrimanis Kyriakos (Department of Pharmaceutical Technology, Aristotle University of Thessaloniki, School of Pharmacy, Thessaloniki, Greece).

\section{Preparation of strock solution}

Standard stock solutions of enalapril were prepared separately by dissolving $50 \mu \mathrm{g}$ of enalapril maleate in $50 \mathrm{ml}$ appropriate solvent. These solutions were prepared freshly every week, during method development and application period.

\section{Preparation of calibration standards}

Calibration standards for enalapril (as maleate salt) $(1.25,2.0,3.0$, $4.0,10.0,20.0,30.0,40$ and $50.0 \mu \mathrm{g} \mathrm{ml}-1)$ were daily prepared from standard stock solutions by appropriate dilution processes using mobile phase.

\section{In vitro dissolution studies}

In vitro dissolution of twelve tablets containing bisoprolol and enalapril was performed using buffer solutions ( $\mathrm{pH} 1.2 ; 4.5 ; 6.8)$ as the dissolution media at $50 \mathrm{rpm}$ using an USP Apparatus II. The dissolution study was carried out in a $900 \mathrm{ml}$ volume of buffer solution at $37{ }^{\circ} \mathrm{C}( \pm 0.5)$ using the paddle method. One ml of sample was withdrawn and replaced with fresh dissolution medium at the time intervals of 5, 15, 30, 45 min. The concentrations of enalapril in samples were determined by the proposed HPLC method [28].

\section{Analytical method validation}

Once the chromatographic and the experimental conditions were established, the method was validated by the determination of the following parameters such linearity range, sensitivity, repeatability, precision, accuracy, and specificity, as per ICH Q2 (R1) guidelines [29].

\section{System suitability parameters}

The chromatographic systems used for analysis must pass system suitability before going to start the experiment. At first HPLC system is stabilized for forty minutes. Inject blank preparation (single injection) and standard preparation (six replicates) and record the chromatograms to evaluate the system suitability parameters such as tailing factor (NMT 1.5), theoretical plate count (NLT 3000) and retention time. The \% RSD for the peak area of six replicate injections of bisoprolol fumarate standard NMT 2.0. The parameters such as tailing factor, \% RSD and theoretical plates were studied.

\section{Linearity}

A standard stock solution of the enalapril maleate was prepared with the same solvent. To study the linearity range of drugs, serial dilutions were made from standard stock solution in the range of $25-200 \%$ of the nominal concentrations of enalapril in the test solution.

\section{Specificity}

Specificity of an analytical method is its ability to measure accurately and specifically the analyte of interest without interference from placebo and degradation products. The specificity of the method was established by injecting blank, placebo and standard solution in triplicate and recording the chromatograms. Blank solution shows no interference with any HPLC system artifact peak. Placebo to demonstrates the lack of interference from excipients.

\section{Precision}

The precision of the method was determined by repeatability (intraday) and intermediate precision (interday). Repeatability was determined by performing repeated analysis of the same working solution of enalapril maleate on the same day, under the same experimental conditions. The intermediate precision of the method was assessed by carrying out the analysis on different days and also by another analyst performing the analysis in the same laboratory (between-analysts).

\section{Accuracy}

The accuracy of a method is defined as the closeness of a measured value to the true value. The recovery studies were carried out at 25$200 \%$ of the target level in the tablet in triplicate each in the presence of placebo.

\section{RESULTS}

\section{Optimization of chromatographic conditions}

Chromatographic condition was optimized in several trials with the variation of the composition of mobile phase and flow rate. Based on the theoretical plates, peak shape and back pressure, the column was selected. The optimized mobile phase composition produced stable and acceptable peak shapes for enalapril and bisoprolol with mixtures of methanol: phosphate buffer solution $(65: 35, \mathrm{v} / \mathrm{v})$ pumped at $1.0 \mathrm{ml} / \mathrm{min}$ flow rate and $225 \mathrm{~nm}$ UV detection wavelength. Therefore, all the experiments were carried out on a C18 column (Hi Qsil C18, $5 \mu \mathrm{m}, 4.6250 \mathrm{~mm}$ ). Under the optimum conditions, enalapril was eluted at $5.33 \mathrm{~min}$.

Representative chromatogram of enalapril maleate in tablets containing bisoprolol and enalapril is presented in fig. 2 .

The resultant chromatograms of blank, standard and sample were compared, the correlation was good between standard and sample and no interference of excipients in blank with drug was observed. Blank solution shows no interference with any HPLC system artifact peak. Placeboto demonstrates the lack of interference from excipients. The representative chromatogram (fig. 2) shows no other peaks in the retention time of bisoprolol and enalapril and retention times did not change. In addition, when the solution prepared from the blank tablet was injected into the HPLC system, no co-eluting peaks were obtained at the retention time of bisoprolol and enalapril.

\section{Method validation}

The proposed method was validated as to linearity range, sensitivity, repeatability, precision, accuracy, and specificity according to the ICH guidelines. 


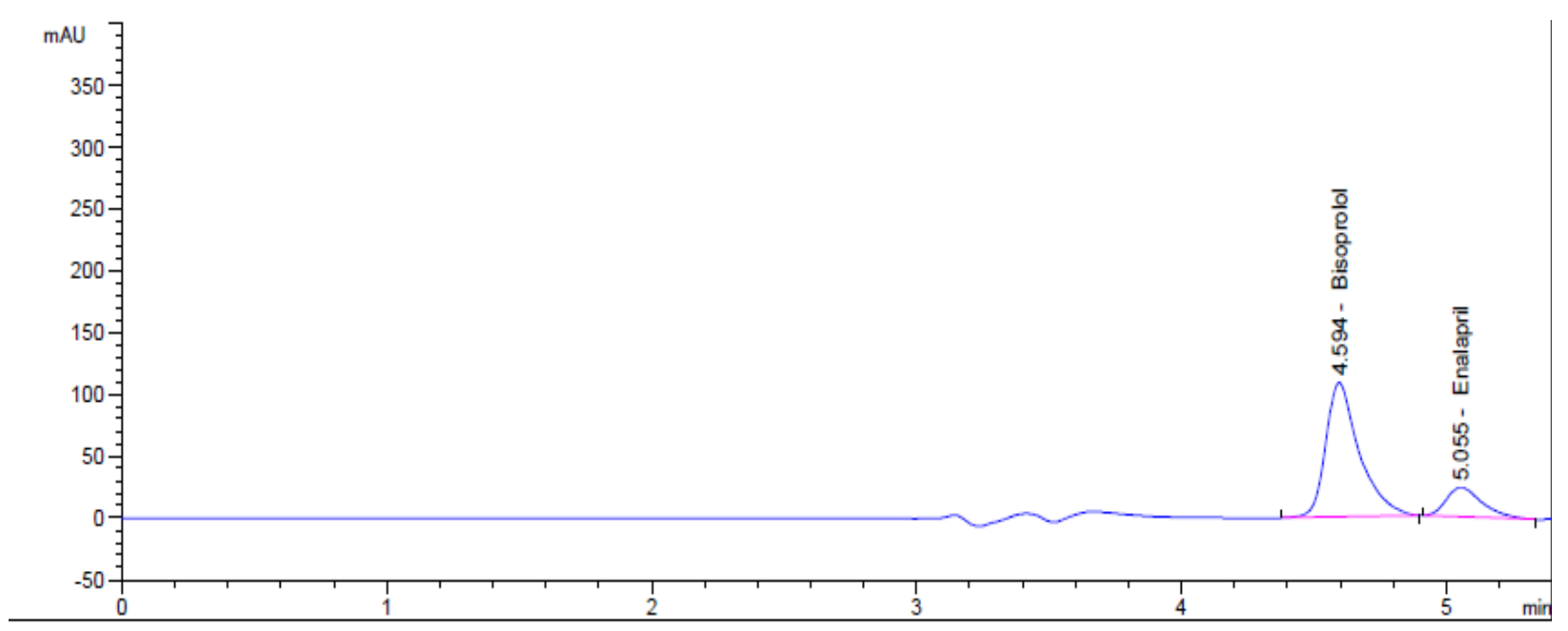

Fig. 2: Representative chromatogram of enalapril maleate in combinated tablets

\section{System suitability}

A suitability test was applied to the chromatograms taken under optimum conditions to check various parameters such as column efficiency (plates), peak tailing, retention factor, and resolution. Suitable resolution $(>2)$ and column efficiency $(>1500$ for both compounds) were achieved for the analysis method. The peak symmetries for both compounds were $<1.2$, whereas the capacity factors were $>1.5$. The analysis time was shorter than $6 \mathrm{~min}$.

\section{Specificity}

Specificity was carried out by evaluation of blank, standard and sample were compared, the correlation was good between standard and sample and no interference of excipients in the blank with the drug was observed. Commonly used tablet excipients did not interfere with this method. It shows that the method is specific. The specificity results are tabulated in table 1 .

Table 1: Specificity study

\begin{tabular}{ll}
\hline Name of the solution & Retention time (tR) min \\
\hline mobile phase & No peaks \\
placebo & No peaks \\
bisoprolol fumarate (another API) & 4.75 \\
Enalapril maleate & 5.33 \\
\hline
\end{tabular}

\section{Linearity range}

Calibration curve representing the relation between the concentrations of drugs versus the peak area was constructed. In triplicate run from which the linear regression equation was calculated. The results obtained were processed by the least squares method. The correlation coefficient of enalapril maleate was noted more than 0.9992 which states that the method was good linear to the concentration versus peak area responses. Results indicate high sensitivity of the proposed HPLC method. The calibration graph of enalapril maleate is presented in fig. $3,4.5$ and characteristics of the linear dependence of enalapril maleate are listed in table 2.

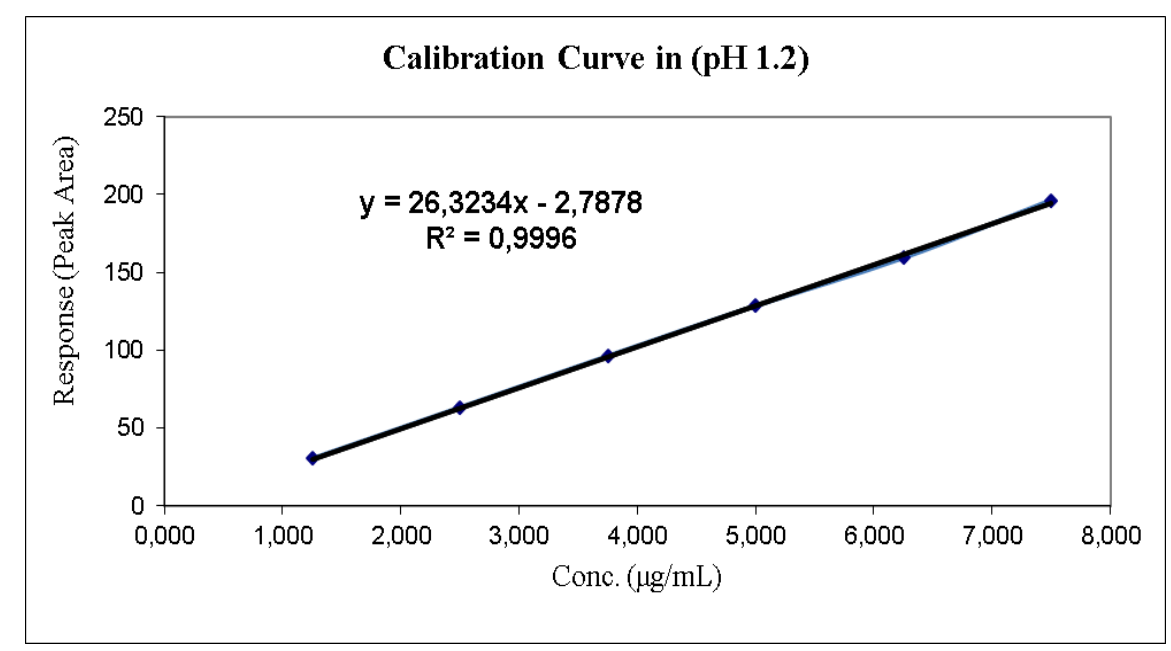

Fig. 3: Linearity on profils of dissolution test at $\mathrm{pH} 1.2$ 


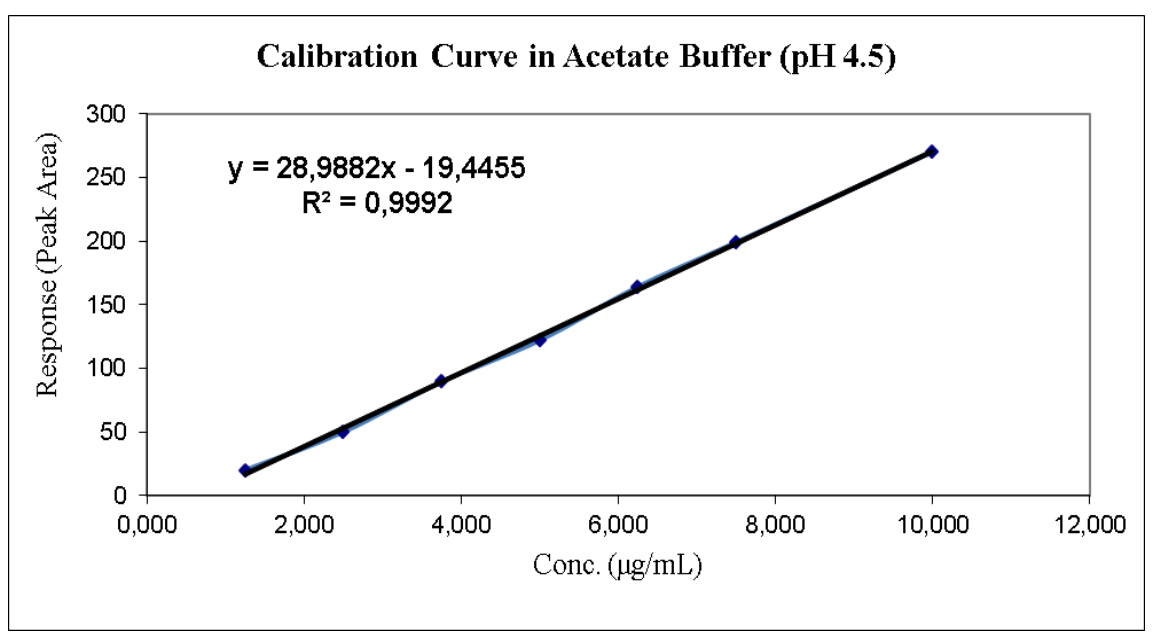

Fig. 4: Linearity on profils of dissolution test at pH 4.5

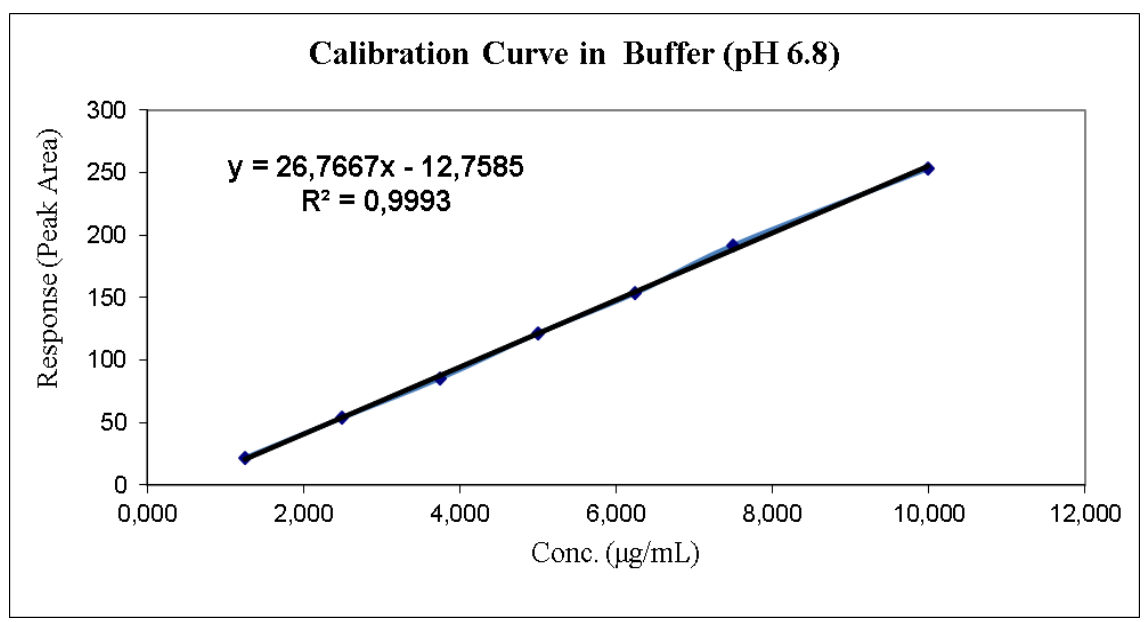

Fig. 5: Linearity on profils of dissolution test at pH 6.8

Table 2: Characteristics of the linear dependence of enalapril maleate

\begin{tabular}{lllll}
\hline $\mathbf{p H}$ & Concentration range $\mathbf{( m g} / \mathbf{m l})$ & Regression equation & $\mathbf{R}^{\mathbf{2}}$ & Compliance with eligibility criteria \\
\hline 1.2 & $1.250-7.500$ & $\mathrm{y}=26.3234 \mathrm{x}-2.7878$ & 0.9996 & Corresponds \\
4.5 & $1.250-10.000$ & $\mathrm{y}=28.9882 \mathrm{x}-19.4455$ & 0.9992 & Corresponds \\
6.8 & $1.250-10.000$ & $\mathrm{y}=26.7667 \mathrm{x}-12.7585$ & 0.9993 & Corresponds \\
\hline
\end{tabular}

A linear relationship between the concentration and the area of chromatographic peaks of enalapril in the range of $1.250 \mathrm{mg} / \mathrm{ml}-10.000 \mathrm{mg} / \mathrm{ml}$ $(7.500 \mathrm{mg} / \mathrm{ml}$ at $\mathrm{pH} 1.2)$ was established (table 1). Requirements for linear dependency parameters are performed in this case throughout the range of application of the technique. Linearity studies were conducted in a wide range of concentrations (25-200\% at pH 4.5 and $6.8,25-150 \%$ at $\mathrm{pH} 1.2)$.

\section{Accuracy and precision}

System precision is shown in table 3. Intra-day and inter-day \% RSD values lower than $2 \%$ clearly assuring that this method was found to be fairly precise and reproducible (table 4). Regarding accuracy, a known amount of the standard drug was added to the fixed amount of pre-analyzed sample solution. \% recovery was calculated by comparing the area before and after the addition of the standard drug. The standard addition method was performed at $25-200 \%$ levels of concentrations. The high value of recoveries obtained for bisoprolol indicates that the proposed method was found to be accurate.

Table 3: Results of system precision $(n=5)$

\begin{tabular}{lll}
\hline Sample & Peak area & Injection no. \\
\hline Enalapril maleate & 1086,486 & 1 \\
& 1086,213 & 2 \\
& 1085,396 & 3 \\
& 1084,526 & 4 \\
& 1085,791 & 5 \\
\hline
\end{tabular}

$\mathrm{n}$ is number of determinations, RSD is relative standard deviation 
Table 4: Intra-day and Inter-day precision data of enalapril maleate $(n=5)$

\begin{tabular}{lllll}
\hline Day & Intra-day precision & & Inter-day precision \\
\cline { 2 - 5 } & Mean & RSD \% & Mean & RSD \% \\
\hline 1 & 100.02 & 0.389 & 101.58 & 0.298 \\
2 & 100.87 & 0.291 & 99.99 & 0.267 \\
3 & 100.92 & 0.329 & 100.15 & 0.317 \\
\hline
\end{tabular}

$\mathrm{n}$ is number of determinations, RSD is relative standard deviation

\section{In vitro dissolution studies}

The average percentage of drugs released as detected by the proposed HPLC method after in vitro dissolution of tablets containing combination drug product are depicted in fig. 6-8.

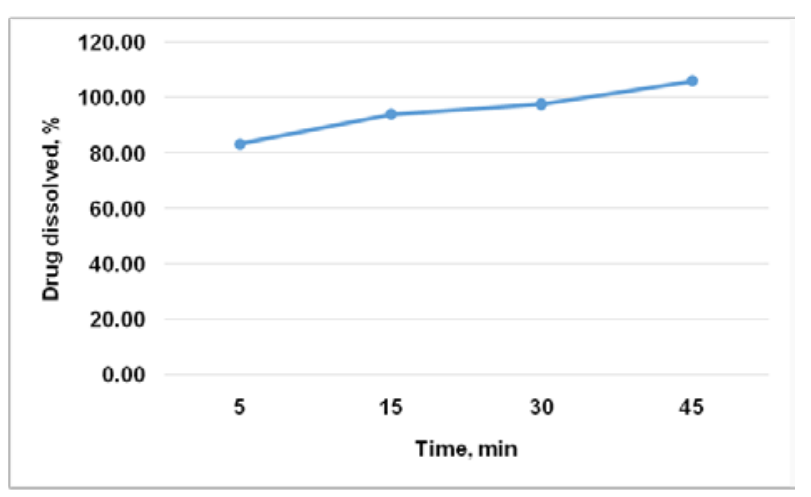

Fig. 6: In vitro dissolution profiles of enalapril at pH 1.2 mean $\pm S D, n=3$

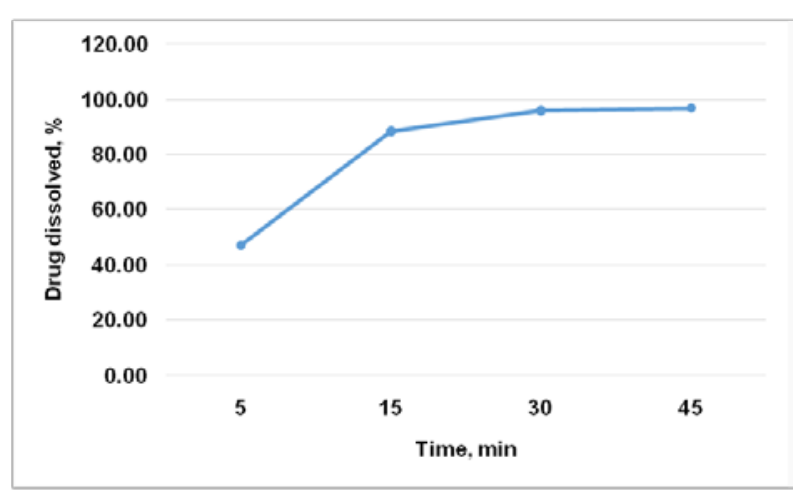

Fig. 7: In vitro dissolution profiles of enalapril at pH 4.5 mean $\pm S D, n=3$

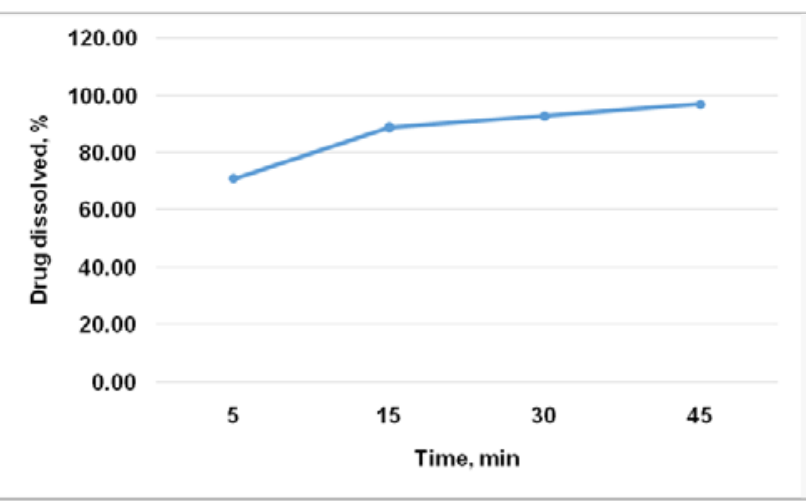

Fig. 8: In vitro dissolution profiles of enalapril at $\mathrm{pH} 6.8$ mean $\pm S D, n=3$
As can be seen from fig. 6-8, in the medium with $\mathrm{pH} 1.2$ release of enalapril from tablets in 5 min is $83.38 \%$, after 15 min- $94.11 \%$, after 30 min-97.17\%; in medium with pH 4.5 the release of enalapril from tablets in 5 min makes $47.13 \%$, after 15 min-88.34 \%, after 30 min-95.86 \%; in a medium with $\mathrm{pH} 6.8$, the release of enalapril from tablets in 5 min is $71.04 \%$, and after 15 min- $88.88 \%$, after 30 min$92.11 \%$.

\section{DISCUSSION}

The present RP-HPLC method is a simple, precise, specific, accurate and linear method for analyzing of enalapril in combinated tablets containing enalapril and bisoprolol. The previous study had reported that UV spectrophotometry methods and HPLC methods for enalapril and bisoprolol individually and in combination with other drugs but not together. In the present RP-HPLC method, we used UV detector which proves selectivity of the method for both APIs. The method was developed by using different buffer ratios at different flow rates. Finally methanol: phosphate buffer solution $(65: 35, v / v)$ as mobile phase and Hi Qsil C 18 (4.6x250 mm, $5 \mu \mathrm{m}$ particle size) column as stationary phase was selected and separation was done for enalaprilat $5.33 \mathrm{~min}$.

The method was validated as per ICH guidelines. Literature survey revealed, stability indicating RP-HPLC method for simultaneous estimation of enalapril with UV detector at different mobile phase and different column. Scientists Manindra M., Zafar H. S. and Ankur K. [30] described HPLC/UV method for the determination of enalapril maleate in tablets using the chromatography column Hypersil MOS, $5 \mu(250 \mathrm{~mm} \times 4.6 \mathrm{~mm})$ and mobile phase-a mixture of buffer solution and acetonitrile $(40: 60, \mathrm{v} / \mathrm{v})$, flow rate $-1.5 \mathrm{ml} / \mathrm{min}$, wavelength detection- $215 \mathrm{~nm}$. Enalapril holding time was $9.72 \mathrm{~min}$, longer than the present method. Compared to the previous method, this method is selective, simple, sensitive, and separation was done at shorter run time. The method was linear in the range of concentrations of $150-250 \mu \mathrm{g} / \mathrm{ml}$, correlation coefficient was 0.9992 .

The first step is to screen formulations with aqueous-based media in the range of $\mathrm{pH} 1.2,4.5,6.8$ at the USP recommended ionic strength. For APIs that exhibit low solubilities in aqueous media throughout the $\mathrm{pH}$ range, the addition of surfactants is recommended. A medium resulting in a gradual increase of released drug up to $100 \%$ is preferred because it is more likely to detect differences in formulation or processing parameters [28].

The method was validated according to ICH guidelines and results were in compliance of ICH guidelines. The linearity of the method had a good correlation with concentration and peak area. The correlation coefficient of enalapril was found to be not less than 0.9992 , which indicates good linear relationship over concentration range $1.250-7.500 / 10.000 \mu \mathrm{g} / \mathrm{ml}$. The \% RSD values in intra-day and inter-day precision study were found to be less than 0.267 for enalapril, which indicate the method was precise. Hence, the present developed method was said to be suitable for the analysis of drugs in their pharmaceutical dosage form. Also, in vitro dissolution of enalapril containing tablets were performed to validate the suitability of the proposed method. The dissolution pattern complies with the FDA standards, indicating the suitability of the proposed method for the dissolution study of enalapril. It will allow conducting comparative studies in vitro to confirm the equivalence of tablets containing enalapril.

\section{CONCLUSION}

A rapid and reproducible RP-HPLC method has been developed for the determination of enalapril in experimental combined dosage 
forms containing bisoprolol and enalapril. The present study of method development and method validation was per ICH guidelines, and it meets the acceptance criteria. The developed method can also be conveniently adopted for dissolution testing of tablets containing enalapril. The proposed method can help research studies, quality control and routine analysis with lesser resources available.

\section{ACKNOWLEDGMENT}

The authors are thankful to Prof. Kachrimanis Kyriakos (Department of Pharmaceutical Technology, Aristotle University of Thessaloniki, School of Pharmacy, and Thessaloniki, Greece) for development experimental tablets.

\section{AUTHORS CONTRIBUTIONS}

All the author have contributed equally

\section{CONFLICT OF INTERESTS}

\section{Declared none}

\section{REFERENCES}

1. https://www.fda.gov [Last accessed on 10 Jan 2019]

2. Niopas I, Daftsios AC, Nikolaidis N. Bioequivalence study of two brands of enalapril tablets after single oral administration to healthy volunteers. Int J Clin Pharmacol Ther 2003;41:226-30.

3. Uslu B, Ozden T. HPLC and UPLC methods for the simultaneous determination of enalapril and hydrochlorothiazide in pharmaceutical dosage forms. Chromatographia 2013;76:1487-94.

4. Walily AM, Belal SF, Heaba EA, Kersh AE. Simultaneous determination of enalapril maleate and hydrochlorothiazide by first-derivative ultraviolet spectrophotometry and highperformance liquid chromatography. Pharm Biomed Anal 1995;13:851-6.

5. Chaudhari BG. Development and validation of Rp-Hplc method for simultaneous stimation of enalapril maleate and amlodipine besylate in combined dosage form. J Appl Pharm Sci 2012;2:547.

6. Liliya Logoyda, Ahmed M Abdel-Megied, Yuliya Kondratova, Olena Trofimenko, Dmytro Korobko, Iryna Dakhym. Development and validation of HPLC method for the simultaneous determination of enalapril maleate in the present of their impurities: application to tablet analysis. Int J Appl Pharm 2018;10:98-102.

7. Yuliya Kondratova, Liliya Logoyda, Yuliia Voloshko, Ahmed Abdel-Megied, Dmytro Korobko, Yuriy Soroka. Development and validation of HPLC-DAD method for the determination of bisoprolol in tablet dosage forms. Int J Appl Pharm 2017;9:549.

8. Kondratova Y, Adebayo T, Logoyda L, Korobko D, Berdey I, Kuchmerovska T. Development of the methodology of the chromatographic determination of amlodipine in medicines. Int J Res Ayurveda Pharm 2016;7:32-5.

9. Liliya Logoyda, Yuliya Kondratova, Dmytro Korobko, Yuriy Soroka. Development of UHPLC method for the determination of captopril in pharmaceutical dosage forms. Asian J Pharm Clin Res 2017;10:308-10.

10. Liliya L, Dmytro K, Olena S, Ihor B, Tamara K. Development of methodology for identification of captopril in medicines. Asian J Pharm 2016;10:168-71.

11. Logoyda L, Korobko D, Saprun S, Zarivna N. Development of methods for the chromatographic identification of active pharmaceutical ingredient from a group of angiotensinconverting enzyme inhibitors in pharmaceuticals. Int J Green Pharm 2017;11 Suppl:737-41.

12. Liliya Logoyda, Dmytro Korobko, Iryna Ivanusa, Kovalenko Serhii. Development of the methodology of the chromatographic determination of nifedipine in medicines. Asian J Pharm Clin Res 2017;10:149-52.

13. Logoyda Liliya, Korobko Dmutro, Saprun Stanislav. Development of methods for identification of calcium channel blockers in medicines. Int J Res Ayurveda Pharm 2016;7:88-91.
14. Olgya Polyauk, Liliya Logoyda. The investigation of conditions of API from group of calcium channel blockers extraction by organic solvents by using high-performance liquid chromatography as method assay. Asian J Pharm Clin Res 2017;10:354-6

15. Kondratova Y, Adebayo T, Logoyda L, Korobko D, Berdey I, Kuchmerovska T. Development of the methodology of the chromatographic determination of amlodipine in medicines. Int J Res Ayurveda Pharm 2016;7:32-5.

16. Logoyda L, Abdel Megied AM, Kondratova Y, Trofimenko O, Korobko D, Dakhym I. Development and validation of HPLC method for the simultaneous determination of enalapril maleate in the present of their impurities: application to tablet analysis. Int J Appl Pharm 2018;10:98-102.

17. Liliya Logoyda, Dmytro Korobko, Oleksandra Oleshchuk, Taras Proniv, Mariya Dmutriv. A HPLC MS/MS method development and validation for the simultaneous determination of bisoprolol and enalapril in the present of enalaprilat in human plasma. Int J Appl Pharm 2018;10:31-40.

18. Logoyda L, Mykhalkiv M, Polyauk O, Zarivna N, Soroka Y, Demydiak 0. Ultra-high-performance liquid chromatography as assay method for the investigation of conditions of captopril extraction by organic solvents. Asian J Pharm 2018;12 Suppl:111-4.

19. Mykhalkiv M, Logoyda L, Polyauk O, Zarivna N, Soroka Y, Ryabokon S, Riabokon M. HPLC as assay method for the investigation of conditions of bisoprolol extraction by organic solvents. Int J Green Pharm 2018;12 Suppl:276-9.

20. Liliya Logoyda. Bioanalytical method development and validation from the simultaneous determination of verapamil and enalapril in the present of enalaprilat by HPLC MS/MS. Int J Appl Pharm 2018;10:19-27.

21. Liliya Logoyda. Quantitative determination of amlodipine from Caco-2 cell monolayers by high-performance liquid chromatography-mass spectrometry/mass spectrometry. Asian J Pharm Clin Res 2018;11:204-7.

22. Mykhalkiv M, Logoyda L, Ivanusa I, Soroka Y, Yakubishyna I. High-performance liquid chromatography as assay method for the investigation of conditions of enalapril maleate extraction by organic solvents. Int J Green Pharm 2018;12:62-5.

23. Logoyda L, Kondratova Y, Korobko D, Susla O, Soroka Y, Tsytsiura R, et al. Youden's test of the chromatographic determination of captopril in pharmaceuticals. Int J Green Pharm 2017;11:188-91.

24. Liliya Logoyda. A HPLC-MS/MS method development and validation for the simultaneous determination of nifedipine and enalapril in human plasma. Int J Appl Pharm 2018;10:35-42.

25. Liliya Logoyda. A high-performance liquid chromatographymass spectrometry method development for the quantitative determination of enalapril maleate from caco-2 cell monolayers. Asian J Pharm Clin Res 2018;11:89-92.

26. Logoyda L, Korobko D. A high-performance liquid chromatography-mass spectrometry/mass spectrometry method development for the quantitative determination of bisoprolol from caco-2 cell monolayers. Asian J Pharm Clin Res 2018;11:386-9.

27. Marushchak M, I Krynytska. Pharmacological treatment of osteoporosis in patients with coronary heart disease complicated by chronic heart Failure. Asian J Pharm Clin Res 2019;12:443-6.

28. Yuryeva O, Kondratova Y, Logoyda L. Development of highperformance liquid chromatography method for the simultaneous analysis of amlodipine and valsartan in combined dosage form and in vitro dissolution studies. Asian J Pharm Clin Res 2018;11:200-4.

29. ICH Q2 (R1), Validation of analytical procedures, Text and methodology. International Conference on Harmonization, Geneva; 2005. p. 1-17.

30. Manindra M, Zafar HS, Ankur K. Validation of stability indicating HPLC method for the determination of enalapril maleate in tablet formulations. Int J Pharm Pharm Sci 2011;3 Suppl 5:180-3. 